\title{
Othon de Grandson chevalier et poète, Études réunies par Jean-François Kosta-Théfaine
}

\section{Maria Colombo Timelli}

\section{(2) OpenEdition}

\section{Journals}

Édition électronique

URL : http://journals.openedition.org/studifrancesi/8173

DOI : 10.4000/studifrancesi.8173

ISSN : 2427-5856

Éditeur

Rosenberg \& Sellier

\section{Édition imprimée}

Date de publication : 1 mai 2009

Pagination : 146-147

ISSN : 0039-2944

\section{Référence électronique}

Maria Colombo Timelli, « Othon de Grandson chevalier et poète, Études réunies par Jean-François

Kosta-Théfaine », Studi Francesi [En ligne], 157 (LIII | I) | 2009, mis en ligne le 30 novembre 2015, consulté le 13 janvier 2021. URL : http://journals.openedition.org/studifrancesi/8173 ; DOI : https:// doi.org/10.4000/studifrancesi.8173

Ce document a été généré automatiquement le 13 janvier 2021.

\section{(c)}

Studi Francesi è distribuita con Licenza Creative Commons Attribuzione - Non commerciale - Non opere derivate 4.0 Internazionale. 


\title{
Othon de Grandson chevalier et poète, Études réunies par Jean-François Kosta-Théfaine
}

\author{
Maria Colombo Timelli
}

\section{RÉFÉRENCE}

Othon de Grandson chevalier et poète, Études réunies par Jean-François KOSTA-THÉFAINE, Orléans, Paradigme, 2007 («Medievalia», 63).

1 Le but de ce recueil, initiative louable due à Jean-François Kosta-Théfaine, est de faire le point sur ce poète de la seconde moitié du XIV e siècle qui demeure mal connu, malgré une série d'études importantes parues surtout au cours des vingt dernières années.

2 C'est à Arthur Piaget que l'on doit, dès la fin du XIx siècle, la redécouverte de l'œuvre d'Othon de Grandson: cela explique la réédition de son article paru dans la «Gazette de Lausanne» en 1889 (Les poésies d'Othon de Grandson, pp. 75-84). Les autres contributions prennent en compte tant les aspects biographiques que littéraires, en se penchant sur l'attribution discutée de certains ouvrages, la tradition textuelle et les formes métriques, les motifs littéraires, les rapports entre Grandson et d'autres grands poètes de son temps.

Daniel chaUbet (Le duel Othon de Grandson - Gérard d'Estavayer du 7 août 1397, pp. 11-42) reconstruit le climat politique de la Savoie au moment de la mort d'Amédée VII (1391), contexte qui explique le duel judiciaire où le chevalier poète trouva la mort six ans plus tard. En annexe, édition de l'ordonnance de gage de messire Girard d'Estavayé et de messire Octhe de Gransson, chevaliers, selon le ms. BnF, fr. 6165 (milieu du Xve siècle).

Joan GRENIER-WINTHER, qui prépare une nouvelle édition critique de l'œuvre de Grandson (à paraître chez Champion), étudie la riche tradition, manuscrite et imprimée, de la Belle dame qui eut mercy (19 manuscrits, quatre incunables, auxquels s'ajoutent des éditions anciennes), afin de vérifier si une attribution à Alain Chartier ou à Othon de 
Grandson peut être envisagée. La conclusion négative - le poème doit demeurer anonyme - n'enlève rien à l'intérêt de cet article, philologiquement remarquable. On trouvera en annexe des tables résumant la tradition des deux poèmes de la Belle dame, la tradition des œuvres de Grandson, le contenu de trois manuscrits particulièrement significatifs: London, Westminster Abbey 21, Paris, BnF fr. 1727 et fr. 1131 (On the Authorship of "La Belle dame qui eut mercy", pp. 43-74).

Catherine ATTWOOD (La dialectique amoureuse chez Othon de Grandson, pp. 85-101) analyse la poésie de Grandson autour de deux noyaux thématiques: une dialectique intérieure, fondée sur l'antithèse (joie/douleur, loin/près, par exemple), et une dialectique extérieure, formelle, ayant recours au débat pour s'exprimer.

6 Heather ARDEN (Othon de Grandson and Christine de Pizan: Love's Martyrs, pp. 103-121) explore la conception de l'amant-martyr dans le Livre Messire Ode (récit de quelque 2500 vers entrecoupés de pièces lyriques et de lettres) et dans le Livre du duc des vrais amans de Christine de Pizan. Malgré quelques analogies, elle doit conclure que le thème du 'martyr d'amour' est traité différemment par les deux poètes.

7 Ian LAURIE, Les amitiés métriques: Othon de Grandson et Eustache Deschamps, pp. 123-136. Témoignée au moins par deux ballades de Deschamps, l'amitié entre les deux poètes se réalise surtout sur le plan métrique: I.L. souligne en particulier l'utilisation de l'envoi et la préférence pour la strophe longue.

8 Hélène BASSO (L'envol et l'ancrage. La quête amoureuse comme épreuve de soi dans "Le Dit de l'Alérion" de Guillaume de Machaut et "Le Livre Messire Ode" d'Othon de Grandson, pp. 137-163). Malgré des échos évidents de l'un à l'autre, le Dit et le Livre exploitent de manière différente le grand thème de la quête amoureuse. Selon H.B., la différence majeure réside dans l'ancrage dans le temps chez Machaut contre un lyrisme qui se situe au dehors de toute dimension temporelle, et par là plus proche de la lyrique traditionnelle, chez Grandson.

9 Alain CORBELLARI, D'Othon de Grandson à Charles-Albert Cingria. La réception romande du 'dernier des trouvères', pp. 165-181. Grand écrivain suisse du xxe siècle, Charles-Albert Cingria découvrit Othon de Grandson grâce à l'édition Piaget (1941), à laquelle il consacra un compte rendu enthousiaste. Cependant, sa profonde conviction que la poésie médiévale - celle de Grandson également - ne pouvait qu'être lyrique, musicale, demeure indubitablement fausse.

10 Complète le volume une bibliographie des œuvres du poète chevalier, avec répertoire des manuscrits et des éditions, et bibliographie critique (pp. 195-201), section accompagnée d'un commentaire de Jean-François KOSTA-THÉFAINE (L'état de la recherche sur Othon de Grandson, pp. 183-194). 